\title{
Paola Laiolo
}

From inter-specific behavioural interactions to species distribution patterns along gradients of habitat heterogeneity

Paola Laiolo

Research Unit of Biodiversity (CSIC, UO, PA)

Oviedo University - Campus de Mieres

33600 Mieres - Spain

E-mail: paola.1aiolo@csic.es

Tel: ++34985103000

Author Contributions: PL conceived, designed, and executed this study and wrote the manuscript. No other person is entitled to authorship 
Abstract The strength of the behavioural processes associated with competitor coexistence may vary when different physical environments, and their biotic communities, come into contact, although empirical evidence of how interference varies across gradients of environmental complexity is still scarce in vertebrates. Here, I analyze how behavioural interactions and habitat selection regulate the local distribution of steppeland larks (Alaudidae) in a gradient from simple to heterogeneous agricultural landscapes in Spain, using crested lark Galerida cristata and Thekla lark G. theklae as study models. Galerida larks significantly partitioned by habitat but frequently co-occurred in heterogeneous environments. Irrespective of habitat divergence, however, the local densities of the two larks were negatively correlated, and the mechanisms beyond this pattern were investigated by means of playback experiments. When simulating the intrusion of the congener by broadcasting the species territorial calls, both larks responded with an aggressive response as intense as when responding to the intrusion of a conspecific with respect to warning and approach behaviour. However, birds promptly responded to playbacks only when congener territories were nearby, a phenomenon that points to learning as the mechanisms through which individuals finely tune their aggressive responses to the local competition levels. Heterospecifics occurred in closer proximity in diverse agro-ecosystems, possibly because of more abundant or diverse resources, and here engage in antagonistic interactions. The drop of species diversity associated with agricultural homogenization is therefore likely to also bring about the disappearance of the behavioural repertoires associated with species interactions.

Key words agroecosystems $\cdot$ calls $\cdot$ competition $\cdot$ habitat heterogeneity $\cdot$ territoriality 


\section{Introduction}

Exclusion, coexistence and evolutionary divergence are the major outcomes of competitive interactions among species (Schluter 2000; Peiman and Robinson 2010). Competition for resources (indirect competition) and resource-related morphological trait divergence have received a great deal of attention because of their significance in speciation and in the evolution of phenotypic diversity (Pfennig and Pfennig 2010). However, in some animal communities, direct, interference competition via antagonistic behaviours is a dominant ecological force describing species interactions (Law and Watkinson 1989; Ord and Stamps 2009), and may play an important role in controlling species abundances (Robinson and Terborgh 1995). Interspecific territorial or despotic behaviours are often associated with underlying interference competition, and have been studied in a variety of vertebrates, especially fishes, amphibians, reptiles and birds (Cody 1974; Myrberg and Thresher 1974; Martin and Martin 2001; Smyers et al. 2002; Adams 2004; Jankowski et al. 2010; Murase and Sunobe 2011; but see also Mikami and Kawata 2004). The major factors determining the maintenance of aggressive territorial behaviours are resource irreplaceability, defensibility and intermediate abundance, as well as the evolution of behavioural strategies that reduce aggression costs (Peiman and Robinson 2010). Interference traits depend on the availability of information on competitors rather than exclusively on energy or nutrient availability, and good sensory capabilities may help reduce the uncertainty of antagonistic outcomes (Vahl 2005; Lehtonen et al. 2010). Consequently, the study of heterospecific interference provides insight into the mechanisms that species use to cope with the surrounding biotic environment, in addition to disentangling the processes underlying species distribution.

To properly understand the ecology of interference it is necessary to distinguish between interference traits (aggressiveness, ritualized signalling, etc.) that mediate certain interactions (e.g. territoriality) and their effect on community structure (niche partitioning) 
(Peiman and Robinson 2010). Since an organism is more likely to compete with neighbouring individuals, however, there are unavoidable local differences in the nature of interactions depending on the spatial distribution of species (Tilman 1994; Gil 1997; Thompson 2005; Grether et al. 2009). Interaction strength may also vary when different physical environments, and their biotic communities, come into contact, although empirical evidence on how heterospecific territoriality and the spatial arrangement of species vary across environmental gradients is still scarce. On the one hand, a high diversity of antagonistic interactions is expected to persist in homogeneous environments without opportunities for much structuring, whereas alternative adaptive mechanisms can evolve in spatially structured environments (ecological displacement; Petren and Case 1998; Reichenbach et al. 2007). On the other hand, interactions may be important in structuring communities in conditions of high environmental productivity, while poor resource availability, or high environmental stress, may result in densities too low for individuals to interfere with resources of neighbours (Noir-Mey 1974). In the latter conditions community structuring mechanisms shift from interaction-based to abiotic stress-based (Menge and Sutherland 1987).

Since intensive agriculture simplifies the structure of landscapes and their biotic communities (Suarez-Seoane et al. 2002; Laiolo 2005), and reduces the availability or variety of resources for wildlife (Benton et al. 2003), agro-ecosystems represent good study systems to address the influence of environmental variation on competitive interactions among species by presenting sharp gradients of habitat structure and productivity (Tscharntke et al. 2005). In this study I use both observations and evidence from experiments simulating territorial intrusion to address the mechanisms and consequences of interference competition across a gradient from simple to complex agricultural habitat matrices in co-existing steppeland birds. I focus on two ecologically and morphologically similar lark species, crested lark Galerida cristata and Thekla G. theklae, which partially segregate by habitat but largely overlap in 
food, feeding habits, communication systems and escape behaviour (Guillaumet et al. 2005; Laiolo et al. 2011; Laiolo 2012). These species respond aggressively to congener territorial calls, which converge in many acoustic properties when larks co-exist in close contact (Laiolo 2012). If interference competition occurs, I expect that the abundance of the two species should be constrained by the density of the congener along with other environmental variables, and that the simulated intrusion of a congener in territories should elicit aggressive responses (Jankowski et al. 2010). Here, I test for these predictions by analyzing the role of the heterogeneity of agricultural habitats in conditioning the intensity of species interactions. If habitat structural diversity permits species to segregate by habitat locally, weaker antagonistic interactions should result (Pons et al. 2008). Conversely, harsher interactions could occur in heterogeneous agro-ecosystems if these present diverse and abundant resources for insectivorous birds (Pain \& Pienkowski 1997; Laiolo et al. 2004; Ursua et al. 2005).

\section{Materials and Methods}

Species distribution and abundance

To describe the distribution and abundance patterns in Galerida larks, I surveyed the species abundance in 80 transects nested in 28 sites in Ebro Valley $\left(9000 \mathrm{~km}^{2}\right.$, north-eastern Spain; Online Resource 1) during the breeding season of 2007 (March-May). In Ebro Valley, traditional and low-intensity land-use practices promoted habitat heterogeneity over the last few centuries, before the rapid agricultural intensification and irrigation schemes of recent decades reduced this diversity to more homogeneous landscapes, with a significant reduction in natural vegetation cover (Brotons et al. 2004; Laiolo and Tella 2006a). Presently, the study area is mostly covered by dry cereal cultivations (40\%), irrigated crops (alfalfa, corn, maize, 
etc.; 16\%), mixed agricultural matrices (orchards and crops interspersed with natural vegetation; $17 \%$ ), and natural vegetation (steppe vegetation; 15\%).

Each transect was $2 \mathrm{~km}$ long, and each bird within a band of $50 \mathrm{~m}$ at each side of the transect was recorded, to derive a measure of species density per 20 ha $(2000 \times 100 \mathrm{~m})$. The nearest neighbouring sites were located $6-23 \mathrm{~km}$ from each other, and the nearest transects were separated by $100 \mathrm{~m}-5.7 \mathrm{~km}$. On average 2.9 transects per site (range 1-10) were walked. To obtain a description of the habitat composition at the transect scale (20 ha), I estimated the percent land use cover within each transect using 2006 CORINE land-use/land-cover digital map with 100 m resolution (source: Instituto Geográfico Nacional: http://www.02.ign.es/ign/layoutIn/coberturaUsoSuelo.do). The habitat types found in transects were classified as: Natural vegetation (steppe lands), irrigated crops, dry cereal cultivations, and mixed agricultural matrices. The relative proportions of land uses were used to obtain an index of habitat heterogeneity (Shannon-Weaver index); the average slope of the transect area was calculated by means of a DEM digital elevation model (Laiolo and Tella 2006b).

To determine which of several alternative models including land use cover, habitat heterogeneity, slope and congener density best explained lark densities, I used generalized linear mixed models (GLMMs) with Poisson distribution of errors. The site was entered as a random factor. The Akaike's Information Criterion (AIC) was used to identify the best and most parsimonious models explaining variation in lark densities, i.e. those accounting for the most variation with the fewest variables (lower AIC values indicate a better approximation) (Buckland et al. 1997). Models were ranked on the basis of the differences between the AIC of a given model and the AIC of the highest ranked model. In order to test for the importance of variables while the effect of other variables is accounted for, an iterative forward variableselection process using the AIC and P-values was used. To minimise the potential for 
overfitting and significance-by-chance effects, the number of models was limited to a set of candidates that was most appropriate and plausible a priori (20 models per species), and included those single variables that significantly affected lark densities and ranked the lowest AIC.

Playback experiment design

Interspecific aggressiveness was tested by means of playback experiments in an area located in the northern Ebro Valley (Online Resource 1), where congeners are located at $<1.5 \mathrm{~km}$ from each other and territories had been surveyed in 2004, 2005, 2007 and 2011 (Laiolo et al. 2011). Prior to playback experiments in 2011, I located individuals and noted their movements and posts to approximate territorial borders, and mapped posts with a GPS to estimate the distance between the nearest congener larks.

Calls for playback stimuli were recorded from 30 G. cristata and 33 G. theklae subjects; these signals are used by larks to advertise territories and repel rivals (Abs 1963). When Galerida larks coexist, as in the study area, the calls of the two species appear to converge as a result of reciprocal learning, stimulating a stronger aggressive reaction in congeners than calls evolved in allopatry (Laiolo 2012). The vocalizations of two species whose home ranges or territories overlap with Galerida larks were used as controls for this study: the Dupont's lark Chersophilus duponti (15 subjects) and the House sparrow Passer domesticus (10 subjects). Subject recordings were obtained by means of Sony TC-D8 DAT and Marantz PMD660 recorders, and a Sennheiser ME67 microphone, during the period 2003-2011. Fifteen individuals per lark species were recorded in Ebro Valley ('local' subjects), while the rest of the Galerida subjects were recorded in other Spanish regions ('distant' subjects: Asturias and eastern Andalucía for G. cristata; Mallorca and southern Andalucía for G. theklae); Dupont's 
larks and House sparrows were recorded in Ebro Valley (Laiolo 2012). Stimuli were created with Avisoft-SasLab Pro using complete vocalization bouts of Galerida and control species, filtered with a high pass filter at $0.8 \mathrm{kHz}$ and normalized to an amplitude of $80 \%$ of a volt. Vocalization bouts were copied and appended several times to create a 4-minute broadcast. Playback experiments lasted 10 minutes: 3 minutes of pre-observation silence were followed by 4 minutes of playback, and then by 3 minutes of silence again. Experiments were performed during breeding in April 2011, from 7:00 to 13:00 and from 18:00 to 19:00, in good weather conditions. Vocalizations were broadcasted with a Marantz PMD660 recorder and Philips SBA1500/37 loudspeaker hidden in shrub vegetation close to individual posts. Overall, 85 G. cristata and 87 G. theklae territories were randomly tested with the call playback of G. cristata, G. theklae, Chersophilus duponti and Passer domesticus subjects. Each stimulus was presented in 1.9 $\pm 0.06 \mathrm{SE}$ territories, i.e. each subject was tested in one $G$. cristata and one G. theklae territory with the exception of one call, which was tested with one species (and individual) only. The playback experiment was aborted and repeated the next day on eight occasions, when territorial individuals approached the playback area prior to broadcasting (during pre-observation silence), or the playback stimulus attracted non-target neighbours.

During 7 minute observations starting at the beginning of playback, I surveyed all movements and vocal activity of larks and six behavioural variables were noted as indices of aggressiveness: the closest distance approached to the speaker and the latency (time) to the closest approach, the latency to call and call bout duration, the latency to singing and song bout duration (Kroodsma 1989 and 1990; McGregor 1992 and 2000). The song is the sexual signal of larks; it is emitted in flight during breeding in the spring and serves to communicate with homospecifics (Laiolo et al. 2011). The position of the closest location of the focal bird and that of the speaker was established with a GPS, in order to calculate the closest distance 
approached. When the distance between the bird and the speaker was $<10 \mathrm{~m}$, a tape measure was used instead. The latency to approach, call and sing was established with a stop-watch. To summarize variation in behavioural parameters, a PCA was performed and two principal components were extracted. PC1 captured variation in approach distance and call activity (correlation with approach distance $=0.78$, latency to approach $=0.76$, latency to call $=0.75$, calling time=-0.76; Eigenvalue $=2.99$; Variance explained $=49.9 \%$; PC2 was mainly associated with singing behaviour (correlation with latency to sing $=0.91$, time spent singing=-0.93; Eigenvalue=1.58, Variance explained=26.4\%) (Online Resource 2).

To analyse whether PC1 and PC2 of behavioural indices varied between species ( $G$. thekla or G. cristata territory) and treatment (congener, conspecific and control vocalizations), GLMMs were performed with a Gaussian distribution of errors, entering playback subject identity and transect as random factors. GLMMs were also used to test whether aggressiveness towards congener larks (PC1 and PC2 of behavioural indices) varied with the distance to the nearest congener, as derived from territory mapping in the experiment area. In all models, I also considered whether playback stimuli were from local (Ebro Valley) or distant larks, in order to control for the greatest aggressiveness toward local congeners shown by Galerida species (Laiolo 2012).

Statistical analyses were performed with R (R Development Core Team 2009) and SPSS 13.0. Markov Chain Monte Carlo (MCMC) algorithms were used for Maximum Likelihood estimation of parameters and $P$-values with GLMM approximation in R (Bates and Maechler 2009; Bolker et al. 2009).

\section{Results}


G. cristata and G. theklae co-occurred in $45 \%$ of the 80 study transects. Significant habitat differences resulted among transects inhabited by both larks, by G. theklae alone, by $G$. cristata alone and by neither of these species. Differences involved habitat heterogeneity $\left(F_{3}\right.$, $\left.{ }_{76}=3.91, P=0.01\right)$, slope $\left(F_{3,76}=6.8, P=0.0004\right)$, and the cover of all habitat types $\left(\right.$ all $F_{3,76}$ $>2.76, P<0.048)$ with the exception of dry cereal fields and complex agricultural matrices $(F$ $3,76<2.52, P>0.09)$. Galerida larks co-occurred most frequently were the habitat was diverse and poorly covered by irrigated lands, and natural vegetation cover was the habitat feature that most discriminated between species (Fig. 1).

The greatest abundance of G. cristata was found in flat, heterogeneous habitats, where the cover of mixed agricultural systems was greatest and that of irrigated crops the lowest, and where the density of G. theklae was low (Table 1A). When G. theklae density was removed from this model, the AIC increased by over 25 points (comparisons between models: $\left.\chi^{2}=27.3, P<0.001\right)$. G. theklae densities peaked in steep slopes, where the cover of irrigated crops was scarce, natural vegetation cover was greatest and, again, where the habitat was most heterogeneous (Table 1B). G. cristata numbers significantly affected G. theklae densities, and model performance worsened if congener density was excluded ( $>13$ AIC points, $\chi^{2}=15.5$, $P<0.001$ ) (Fig. 2). The full list of models tested and their ranking on the basis of AIC values is shown in Online Resource 3.

The negative relationship between lark densities was maintained when considering only the 36 transects where the two species coexisted (GLMMs: all $z>-3.4, P<0.001$ ). The abundance of Galerida individuals in co-occurrence transects was only $18 \%$ higher than where only one species was found: the mean density in transects with both larks was $16 \pm 1$ SE individuals/10 ha; with G. theklae only $13 \pm 4$ individuals/10 ha; with G. cristata only 12 \pm 1 individuals/10 ha. Differences in Galerida densities were significant only between 
transects with both larks and those where only G. cristata occurred (GLMM: z-value=2.8. $P=0.004)$.

In playback areas where the habitat was most heterogeneous, the distance between the nearest congeners was on average shorter than in homogenous areas $\left(r_{11}=0.63, P=0.036\right)$. Galerida larks showed the greatest calling intensity and shortest approach distance (PC1 of behavioural responses to playback) when exposed to conspecific and congener stimuli compared to the playbacks of Chersophilus and Passer vocalizations (GLMM, all $t>4.8$, $P<0.01$ ), whereas responses to conspecific and congener calls did not differ significantly $(t=0.91$, n.s.). The song response (PC2), however, was more pronounced when conspecific calls were broadcasted (comparisons with congener and control stimuli, all $t>2.9, P<0.003$ ), and congener calls elicited a similar response to control songs (all $t<1.4, P>0.17$ ) (Online Resource 4). Calling and approach responses to congener stimuli were more intense when congener territories were close, whereas no significant differences resulted with respect to song activity (PC2) (Table 2; Fig. 4). The two species did not differ in the intensity of their response to the simulated intrusion of the congener (PC1: $t=0.2, P=0.98$; PC2: $t=1.3, P=0.19$; Table 2).

\section{Discussion}

Animal communities often contain ecologically or taxonomically similar species, whose coexistence may lead to resource and habitat partitioning, one of the important mechanisms through which sympatric species avoid competition (Ricklefs 1987). This study shows that heterospecific territoriality and despotic behaviours may also accompany significant habitat segregation, especially in heterogeneous environments where mutually exclusive territories are maintained by territorial behaviours finely tuned to the local social conditions. The 
homogenization of the agricultural matrix negatively affected the abundances of the two species, and this effect on populations was associated with the decline of interspecific interactions, resulting in a drop of diversity at different levels of the biological hierarchy (species and interactions).

Species distribution and antagonistic interactions

Congener density affected the abundances of both lark species, and models including only environmental variables (habitat and topography) performed worse than models including congener density among predictors. Similar results were obtained by distribution models of Galerida spp. performed by Guillaumet et al. (2010). Here, however, playback experiments provided the experimental support lacking in previous studies: both larks responded to the simulated intrusion of a congener with a call and approach behaviour as intense as when responding to the intrusion of a conspecific. The response of the two species to playback stimuli appears to be symmetrical since no significant difference was found in aggressiveness between species (Table 2). This behavioural similarity is usually interpreted as a lack of hierarchy between species in resource exploitation (Jankowski et al. 2010). If no species is dominant over the other, the habitat segregation shown by Galerida species should respond to real habitat preferences, not to interspecific density-dependent habitat shifts (Rosenzweig et al. 1984; Pearson and Rohwer 2000). This idea is also supported by the fact that in the absence of the congener no competitive release has been observed, and both species preferentially occupy their favourite habitats in allopatry (shrub vegetation for G. theklae and cereal cultivations for G. cristata; Laiolo 2012). Therefore, it appears that both heterospecific territoriality and niche partitioning are contributing to the distribution patterns of Galerida species in highly heterogeneous sympatric environments. 
Theoretically, interspecific interference is maintained when its cost is small and the resource overlap among competing species is high (Case and Gilpin 1974). The competitive ability of species is improved, for instance, by traits related to resource defence or competitor offence, which mediate competition and reduce the costs for the individual (Gill 1974; Peiman and Robinson 2010). Galerida larks have very similar foraging habits and diet during breeding, thus resource overlap is high (Hodar 1995; Guillaumet et al. 2005, 2008 and 2010). They maintain territories by uttering territorial calls, and these are acoustically convergent between species when larks co-exist in close contact, a phenomenon possibly driven by frequent interspecific interactions (Laiolo 2012). This form of long distance communication permits spatial segregation without the need to engage harmful and costly territorial disputes, either with conspecifics or congeners (Laiolo 2012).

Galerida species share a long history of local range contractions and expansions due to successional events, but changes driven by modern agricultural activities are proceeding faster than natural events (Suarez et al. 2009). A great behavioural flexibility is required to successfully cope with these anthropogenic shifts and, indeed, Galerida responses are context-dependent and finely tuned to the likelihood of encountering congeners: individuals promptly respond to simulated intrusions only when they are in close contact with territorial congeners, and the aggressive response declines with distance. This finding points to learning as an important mechanism through which matching between behaviour and competition levels is achieved. Researchers have shown plastic aggressions based on recognising threat levels in both territorial birds (Jankowski et al. 2010) and fishes (Lehtonen et al. 2010). The pattern of declining aggressiveness with distance also dismisses the idea that Galerida larks misdirect their responses by erroneously identifying congeners as conspecifics, in which case the response is not expected to vary with distance. Moreover, the fact that the song, an interand intra-sexual signal, is uttered when conspecific intrusion is simulated further strengthens 
the idea that Galerida species are not misdirecting aggression. A conspecific entering a territory represents an additional threat for territorial males, since cuckoldry associated with extra-pair paternity is common in the lark family, and flight songs may also serve to guard mates (Donald 2004; Sanchez et al. 2004).

Habitat homogenization and the diversity of competitive interactions

Heterogeneous farmlands have been shown to provide the greatest variety and abundance of resources for open habitat birds from Spanish steppelands (Rodriguez et al. 2006; Guerrero et al. 2010), also from the Ebro Valley study area (Blanco et al. 1998; Tella et al. 1998). In particular, edge habitats and the ecotone between steppe vegetation and cereal fields can be especially rich in prey (Ursua et al. 2005). For this reason, these habitats may be preferentially occupied by the two antagonistic Galerida species, which would here engage in territorial disputes. Interference could then propel the evolution of context-dependent mimicry and convergence of territorial calls, to reduce the fitness costs of harmful disputes (Laiolo 2012). On the other hand, in the agro-ecosystem under study there is not much opportunity for spatial segregation between species, even in the most heterogeneous habitats, which are characterized by structurally-simple vegetation (low and sparse steppelands and cereal fields) (Vögeli et al. 2010). In a more structurally complex scrubland environment, Pons et al. (2008) have studied the coexistence of Mediterranean warblers, and indeed found that Sylvia and Hippolais species did segregate by micro-habitat and interspecific territoriality has not been described. All in all, if interference competition peaks as a result of high availability of resources, the Galerida system would provide further evidence to the stress-gradient hypothesis, predicting that competitive interactions are important in structuring communities in productive ecosystems but decline in stressful conditions (Daleo and Iribarne 2009) 
A growing body of evidence supports the view that local interactions may vary in strength across gradients of habitat complexity, sometimes resulting in greater functional (interaction) diversity in more complex or heterogeneous habitats (Tscharntke et al. 2008). Anthropogenic activities are creating sharp gradients in habitat heterogeneity, and agroecosystems represent favourite arenas for the study of interactions across structural complexity gradients, since they include both simple (high impact) and complex (low impact) landscapes (Flynn et al. 2009). On one extreme of the gradient, intensive agricultural activities often negatively impact species richness by homogenizing the landscape (Laiolo 2005), skewing the relative abundance of species (Firbank et al. 2008), and inevitably affecting diversity functions (pollination, seed dispersal, etc.) (Fahrig et al.2011). On the other hand, structurally complex rural matrices enhance local diversity, and may partially compensate for local high-intensity management (Tscharntke et al. 2005). This study provides evidence that habitat heterogeneity also increases the diversity of behavioural interactions among farmland species and learning is the likely mechanism through which birds finely tune their aggressive response to local competition levels. In this context, habitat homogenization caused by agricultural intensification not only reduces the diversity of species in the landscape, but also that of interactions and the associated behavioural displays.

Acknowledgements I am very grateful to Bardenas Reales Natural Park, A. Urmeneta and E. Ursua for offering logistic support and hosting me during field work in Ebro Valley, and to D. Serrano for providing information on Galerida populations in Ebro Valley. D. Morris, J.R. Obeso, P. Pons, O. Olsson and one anonymous referee provided useful comments on an early version of the manuscript. The research was funded by the Spanish Ministry of Science and Innovation (CGL2008-02749 grant).

\section{References}


Abs M (1963) Vergleichende untersuchungen an Haubenlerche (Galerida cristata L.) Bonn Zool Beitr 14:1-128

Adams DC (2004) Character displacement via aggressive interference in Appalachian salamanders. Ecology 85: 2664 - 2670.

Bates D, Maechler M (2009) lme4: Linear mixed-effects models using S4 classes. R package version 0.999375-32. http://CRAN.R-project.org/package=lme4

Benton TG, Vickery JA, Wilson JD (2003) Farmland biodiversity: is habitat heterogeneity the key? Trends Ecol Evol 18: 182-188.

Blanco G, Tella JL, Torre I (1998) Traditional farming and key foraging habitats for chough Pyrrhocorax pyrrhocorax conservation in a Spanish pseudosteppe landscape. J Appl Ecol 35: $232-239$.

Bolker BM, Brooks ME, Clark CJ, Geange SW, Poulsen JR, Stevens MHH, White JSS (2009) Generalized linear mixed models: a practical guide for ecology and evolution. Trends Ecol Evol 24: 127-135.

Brotons L, Mañosa S, Estrada J (2004) Modelling the effects of irrigation schemes on the distribution of steppe birds in Mediterranean farmland. Biodiv Conserv 13:1039-1058.

Buckland ST, Burnham KP, Augustin NH (1997) Model selection: an integral part of inference. Biometrics 53: 603-618.

Case TJ, Gilpin ME (1974) Interference competition and niche theory. Proc Nat Acad Sci USA 71: 3073-3077.

Cody ML (1974) Competition and the structure of bird communities. Princeton University Press. Princeton, NJ.

Daleo P, Iribarne O 2009. Beyond competition: the stress-gradient hypothesis tested in plantherbivore interactions. Ecology 90: 2368-2374.

Donald PF (2004) The Skylark. London. T. and AD Poyser. 
Fahrig L, Baudry J, Brotons L, Burel FG, Crist TO, Fuller FG, Sirami C, Siriwardena GM, Martin JL (2011) Functional landscape heterogeneity and animal biodiversity in agricultural landscapes. Ecol Lett 14: 101-112

Firbank LG, Petit S, Smart S, Blain A, Fuller RJ (2008) Assessing the impacts of agricultural intensification on biodiversity: a British perspective. Phil Trans R Soc B 363:777-787

Flynn DF, Gogol-Prokurat M, Nogeire T, Molinari N, Richers BT, Lin BB, Simpson N, Mayfield MM, DeClerck F (2009) Loss of functional diversity under land use intensification across multiple taxa. Ecol Lett 12: 22-23

Gill DE (1974) Intrinsic rate of increase, saturation density, and competitive ability. Am Nat 108: 103-116.

Gil D (1997) Increased response of the short-toed treecreeper Certhia brachydactyla in sympatry to the playback of the song of the common treecreeper C. familiaris. Ethology 103: $632-641$.

Grether GF, Losin N, Anderson CN, Okamoto K (2009) The role of interspecific interference competition in character displacement and the evolution of competitor recognition. Biol Rev 84:617-635

Guerrero I, Martínez P, Morales MB, Oñate JJ 2010. Influence of agricultural factors on weed, carabid and bird richness in a Mediterranean cereal cropping system. Agric Ecosyst Environ 138: 103-108

Guillaumet A, Gonin J, Prodon R, Crochet PA (2010) The geographic and seasonal dimensions of habitat use in Galerida larks: implications for species coexistence and range limits. Ecography 33: 961-970.

Guillaumet A, Ferdy JB, Desmarais E, Godelle B, Crochet PA (2008) Testing Bergmann's rule in the presence of potentially confounding factors: a case study with three species of Galerida larks in Morocco. J Biogeogr 35: 579-591. 
Guillaumet A, Crochet PA, Godelle B (2005) Phenotypic variation in Galerida larks in Morocco: the role of history and natural selection. Mol Ecol 14: 3809-3821

Hodar JA (1995) Diet of the Thekla lark, Galerida theklae, in a shrubsteppe of southeastern Spain, Doñana. Doñana Acta Vertebrata 22: 110-114.

Jankowski JE, Robinson SK, Levey DJ (2010) Squeezed at the top: Interspecific aggression may constrain elevational ranges in tropical birds. Ecology 91:1877-1884

Kroodsma DE (1989) Suggested experimental designs for song playbacks. Anim Behav $37: 600-609$.

Kroodsma DE (1990) Using appropriate experimental designs for intended hypotheses in 'song' playbacks, with examples for testing effects of song repertoire size. Anim Behav 40:1138-1150

Laiolo P (2005) Spatial and seasonal patterns of bird communities in Italian agroecosystems. Conserv Biol 19: 1547-1556.

Laiolo P (2012) Interspecific interactions drive cultural coevolution and acoustic convergence in syntopic species. J Anim Ecol 81: 594-604.

Laiolo P, Dondero F, Ciliento E, Rolando A 2004. Consequences of pastoral abandonment for the structure and diversity of the alpine avifauna. J Appl Ecol: 41: 294-304.

Laiolo P, Obeso JR, Roggia Y (2011) Mimicry as a novel pathway linking biodiversity functions and individual behavioural performances. Proc R Soc B 278: 1072-1081

Laiolo P, Tella JL (2006a) Fate of unproductive and unattractive habitats: recent changes in Iberian steppes and their effects on endangered avifauna. Environ Conserv 33: 223-232.

Laiolo P, Tella JL (2006b) Landscape bioacoustics allows detection of the effects of habitat patchiness on population structure. Ecology 87: 1203-1214

Lehtonen TK, McCrary JK, Meyer A (2010) Territorial aggression can be sensitive to the status of heterospecific intruders. Behav Processes 84: 598-601. 
Law R, Watkinson AR (1989) Competition. In Ecological Concepts (ed. Cherrett, J. M.) Blackwell Scientific, London.

Martin PR, Martin TE (2001) Behavioral interactions between coexisting species: song playback experiments with wood warblers. Ecology 82: 207-218.

McGregor PK (2000) Playback experiments: design and analysis. Acta Ethol 3:3-8.

McGregor PK (1992) Quantifying responses to playback: one, many or multivariate composite measures? In: McGregor PK (Ed) Playback and studies of animal communication. Plenum Press, New York, pp 79-96

Menge BA, Sutherland JP (1987) Community regulation: Variation in disturbance, competition, and predation in relation to environmental stress and recruitment. Am Nat 130:730-757.

Mikami OK, Kawata M (2004) Does interspecific territoriality reflect the intensity of ecological interactions? A theoretical model for interspecific territoriality. Evol Ecol Res 6: 765-777.

Murase A, Sunobe T (2011) Interspecific territoriality in males of the tube blenny Neoclinus bryope (Actinopterygii: Chaenopsidae). J Ethol 29: 467-472.

Myrberg AA Jr, Thresher RE (1974) Interspecific aggression and its relevance to the concept of territoriality in reef fishes. Am Zool 14: 81-96

Noy-Meir I (1974) Desert ecosystems: higher trophic levels. Ann Rev Ecol Syst 5: 195-214

Ord TJ, Stamps JA (2009) Species Identity Cues in Animal Communication. Am Nat $174: 585-593$

Pain DJ, Pienkowski MW (1997) Farming and birds in Europe: the common agricultural policy and its implications for bird conservation. Academic Press, San Diego (USA)

Pearson SF, Rohwer S (2000) Asymmetries in male aggression across an avian hybrid zone. Behav Ecol 11: 93-101. 
Peiman KS, Robinson BW (2010) Ecology and evolution of resource-related heterospecific aggression. Q Rev Biol 85: 133-58

Petren K, Case TJ (1998) Habitat structure determines competition intensity and invasion success in gecko lizards. Proc Nat Acad Sci USA 95: 11739-11744

Pfennig DW, Pfennig KS (2010) Character displacement and the origins of diversity. Am Nat 176: S22-S44

Pons P, Bas JM, Prodon R, Roura-Pascual N, Clavero M (2008) Territory characteristics and coexistence with heterospecifics in the Dartford warbler Sylvia undata across a habitat gradient. Behav Ecol Sociobiol 62: 1217-1228.

Reichenbach T, Mobilia M, Frey E (2007) Mobility promotes and jeopardizes biodiversity in rock-paperscissors games. Nature 448: 1046-9.

Ricklefs RE (1987) Community Diversity: Relative Roles of Local and Regional Processes. Science 235: 167-171

Robinson SK, Terborgh J (1995) Interspecific aggression and habitat selection by Amazonian birds. J Anim Ecol 64: 1-11.

Rodríguez C, Johst K, Bustamante J (2006) How do crop types influences breeding success in lesser kestrels through prey quality and availability? A modelling approach. J Appl Ecol 43: $587-597$

Rosenzweig ML, Abramsky Z, Brand S (1984) Estimating species interactions in heterogeneous environments. Oikos 45: 339-348.

Sánchez AM, Herranz J, Martínez, Suarez F (2004) Extra-pair paternity in Short-toed and Lesser Short-toed Larks Calandrella brachydactyla and C. rufescens. Bird Study 51: $278-279$

Schluter D (2000) The ecology of adaptive radiation. Oxford series in Ecology and Evolution. Oxford Univ. Press, New York. 
Smyers SD, Rubbo MJ, Townsend VR, Swart CC (2002) Intra- and interspecific characterizations of burrow use and defense by juvenile ambystomatid salamanders. Herpetologica 58: 422-42.

Suarez F, Hervás I, Herranz J (2009) Las alondras de España peninsular. Dirección general para la biodiversidad. MARM. Madrid.

Suárez-Seoane S, Osborne PE, Baudry J (2002). Responses of birds of different biogeographic origins and habitat requirements to agricultural land abandonment in northern Spain. Biol Conserv 105: 333-344.

Tilman D (1994). Competition and Biodiversity in Spatially Structured Habitats. Ecology 75: 2-16.

Tella JL, Forero M, Hiraldo F, Donázar JA 1998. Conflicts between Lesser Kestrel conservation and European Agricultural Policies as identified by habitat use analyses. Conserv Biol 12: 593-604

Thompson JN (2005) The Geographic Mosaic of Coevolution. Univ. of Chicago Press. Tscharntke T, Sekercioglu CH, Dietsch TV, Sodhi NS, Hoehn P, Tylianakis JM (2008) Landscape constraints on functional diversity of birds and insects in tropical agroecosystems. Ecology 89: 944-951.

Tscharntke T, Klein A.M, Kruess A, Steffan-Dewenter I, Thies C (2005) Landscape perspectives on agricultural intensification and biodiversity - ecosystem service management. Ecol Lett 8: 857-874.

Ursúa E, Serrano D, Tella JL (2005) Does land irrigation actually reduce foraging habitat for breeding lesser kestrels? The role of crop types. Biol Conserv 122: 643-648.

Vahl WK, Van der Meer J,Weissing FJ, Van Dullemen D, Piersma T (2005) The mechanisms of interference competition: two experiments on foraging waders. Behav Ecol 16: 845855. 
Vögeli M, Serrano D, Pacios F, Tella JL 2010. The relative importance of patch habitat quality and landscape attributes on a declining steppe-bird metapopulation. Biol Conserv 143: 1057-1067. 


\section{Figure Legends}

Fig. 1. Habitat features characterizing transects inhabited by Galerida cristata, by G. theklae, by both species, and by neither of these species. Mean and SE of the percent cover of each habitat type are shown, as well as results of post-hoc LSD tests $\left({ }^{*} P<0.05\right.$, ** $P<0.01$, $* * * P<0.001)$

Fig. 2. Relationship between Galerida cristata and G. theklae densities within transects, after removing the effects of those habitat parameters that significantly affected their abundances.

Fig. 3. Relationship between PC1 of behavioural response to playbacks of congener calls and distance to the nearest congener. Dashed line and open dots: G. cristata, Solid line and dots: G. theklae. 
Table 1. Results of GLMM testing for the determinants of Galerida cristata and G. theklae densities. Site identity was entered as a random factor, and sample size corresponds to 80 transects nested within 28 sites. ${ }^{*} P<0.05,{ }^{*} P<0.01, * * * P<0.001$. The full list of models tested is listed in Online Resource 3.
A) Galerida cristata

$\quad$ Model 1 (AIC=260.4)
Intercept
Cover of irrigated crops
Cover of complex agricultural matrices
Slope
Galerida theklae density

$\begin{array}{ccl}\text { Estimate } & \text { SE } & Z \text { value } \\ 2.21 & 0.22 & 9.9^{* * *} \\ -0.007 & 0.003 & 2.2^{*} \\ 0.005 & 0.002 & 2.3^{*} \\ -0.08 & 0.03 & 2.4^{*} \\ -0.07 & 0.01 & 5.0^{* * *}\end{array}$

$\quad$ Model $2(\mathrm{AIC}=260.8)$
Intercept
Cover of irrigated crops
Cover of complex agricultural matrices
Habitat heterogeneity
Cover of dry cereal cultivations
Slope
Galerida theklae density

$\begin{array}{ccl}\text { Estimate } & \mathrm{SE} & Z \text { value } \\ 1.97 & 0.27 & 9.8^{* * *} \\ -0.007 & 0.004 & 2.0^{*} \\ 0.007 & 0.003 & 2.6^{* *} \\ 0.54 & 0.37 & 1.4 \\ 0.003 & 0.002 & 1.4 \\ -0.09 & 0.03 & 2.5^{*} \\ -0.07 & 0.01 & 4.8^{* * *}\end{array}$

Model 3 (AIC=260.9)
Intercept
Cover of irrigated crops
Cover of complex agricultural matic
Habitat heterogeneity
Slope
Galerida theklae density
Model 4 (AIC=261.6)
Intercept
Cover of irrigated crops
Cover of natural vegetation
Habitat heterogeneity
Slope
Galerida theklae density

B) Galerida theklae

$\begin{array}{ccl}\text { Estimate } & \mathrm{SE} & Z \text { value } \\ 2.19 & 0.22 & 9.8^{* * *} \\ -0.009 & 0.003 & 2.4^{*} \\ 0.005 & 0.002 & 2.2^{*} \\ 0.45 & 0.37 & 1.3 \\ -0.08 & 0.03 & 2.4^{*} \\ -0.08 & 0.02 & 5.2^{* * *}\end{array}$

$\begin{array}{ccl}\text { Estimate } & \mathrm{SE} & Z \text { value } \\ 2.3 & 0.22 & 10.4^{* * *} \\ -0.011 & 0.004 & 3.0^{*} \\ -0.004 & 0.002 & 2.0^{*} \\ 0.6 & 0.37 & 1.6 \\ -0.06 & 0.03 & 2.4^{*} \\ -0.08 & 0.01 & 5.2 * * *\end{array}$

Model $1(\mathrm{AIC}=239.4)$

Estimate $\quad \mathrm{SE} \quad Z$ value 
Intercept

Cover of irrigated crops

Cover of natural vegetation

Habitat heterogeneity

Slope

Galerida cristata density $\begin{array}{lll}0.45 & 0.34 & 1.3\end{array}$

$\begin{array}{lll}-0.03 & 0.009 & 3.1 * *\end{array}$

$0.01 \quad 0.003 \quad 3.3 * *$

$2.38 \quad 0.56 \quad 4.3 * * *$

$0.20 .03 \quad 5.7 * * *$

$\begin{array}{lll}-0.06 & 0.02 & 3.8 * * *\end{array}$ 
Table 2. Results of GLMM testing for the determinants of the behavioural response to congener playback. A Principal Component Analysis PCA on six behavioural indices was performed: PC1 expressed variation in calling and approach behaviour, PC2 was mainly associated with singing behaviour. The identity of playback subject (individual) and transect were entered as random factors. Sample size corresponds to 60 Galerida individuals tested with the calls from 47 congeners. ${ }^{*} P<0.05$

PC1 of behavioural response Intercept

$\begin{array}{ccc}\text { Estimate } & \mathrm{SE} & t \\ -0.51 & 0.31 & 1.6 \\ 0.24 & 0.26 & 0.02 \\ -0.74 & 0.26 & 2.9^{*} \\ 0.001 & 0.0004 & 2.2^{*}\end{array}$

Population (Distant vs. local call playback)

Distance to the closest congener

$\begin{array}{ccc}\text { Estimate } & \text { SE } & t \\ 0.93 & 0.31 & 3.0^{* *} \\ -0.34 & 0.25 & 1.3 \\ -0.64 & 0.25 & 2.5^{*} \\ -0.0006 & 0.0004 & 1.6\end{array}$


Fig. 1.
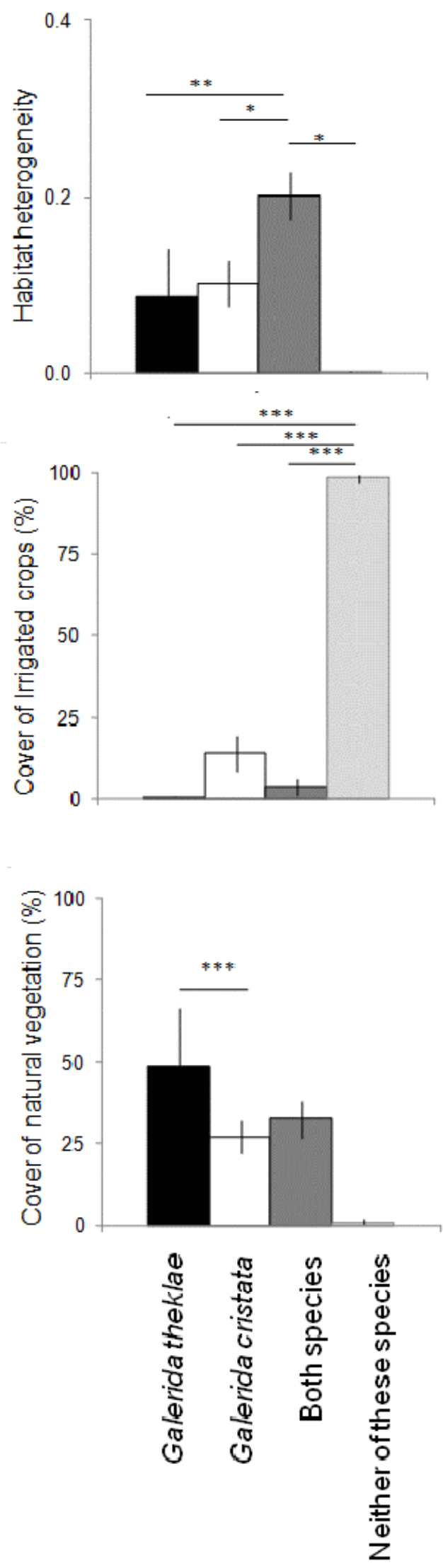
Fig. 2

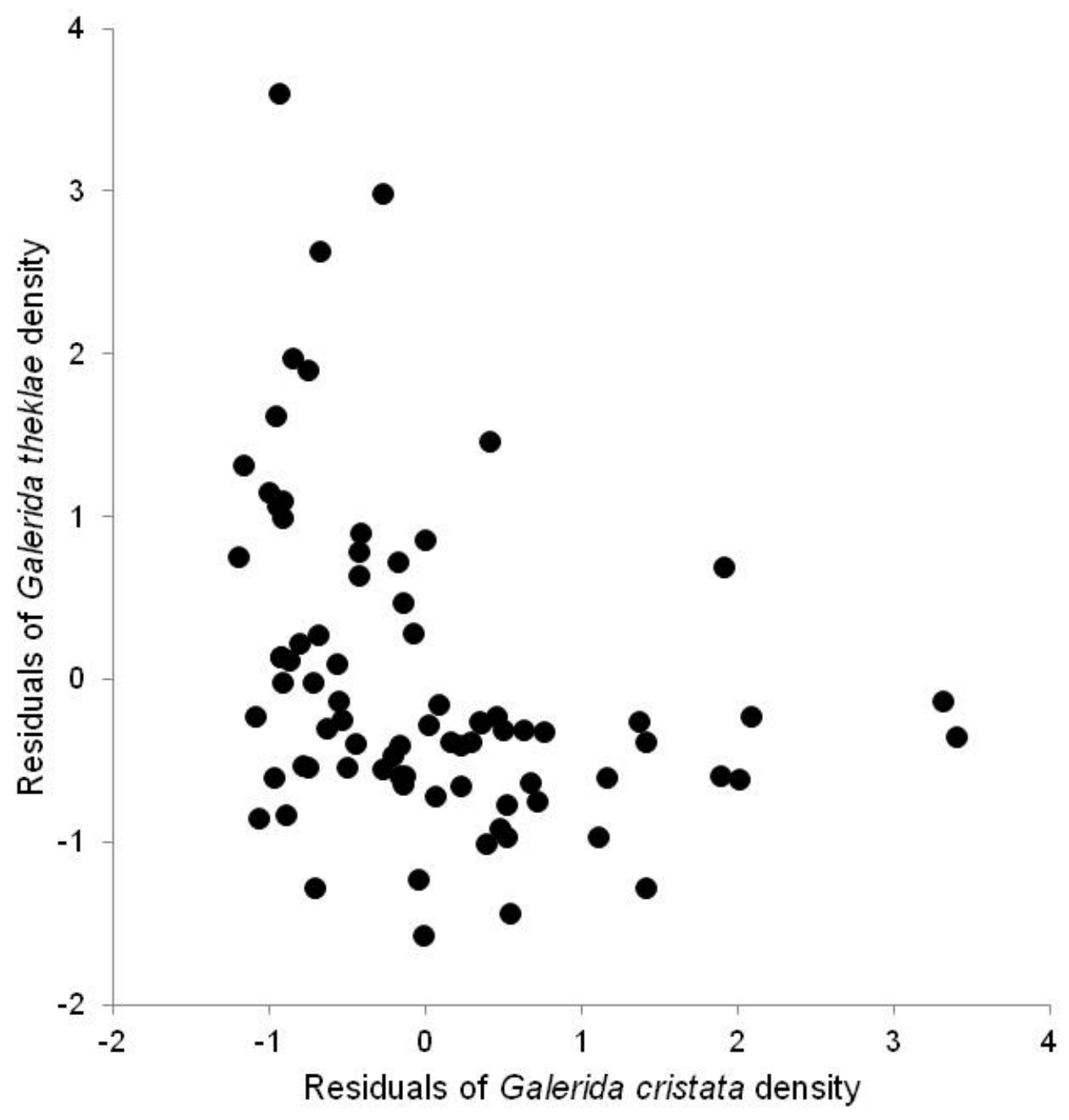


Fig. 3

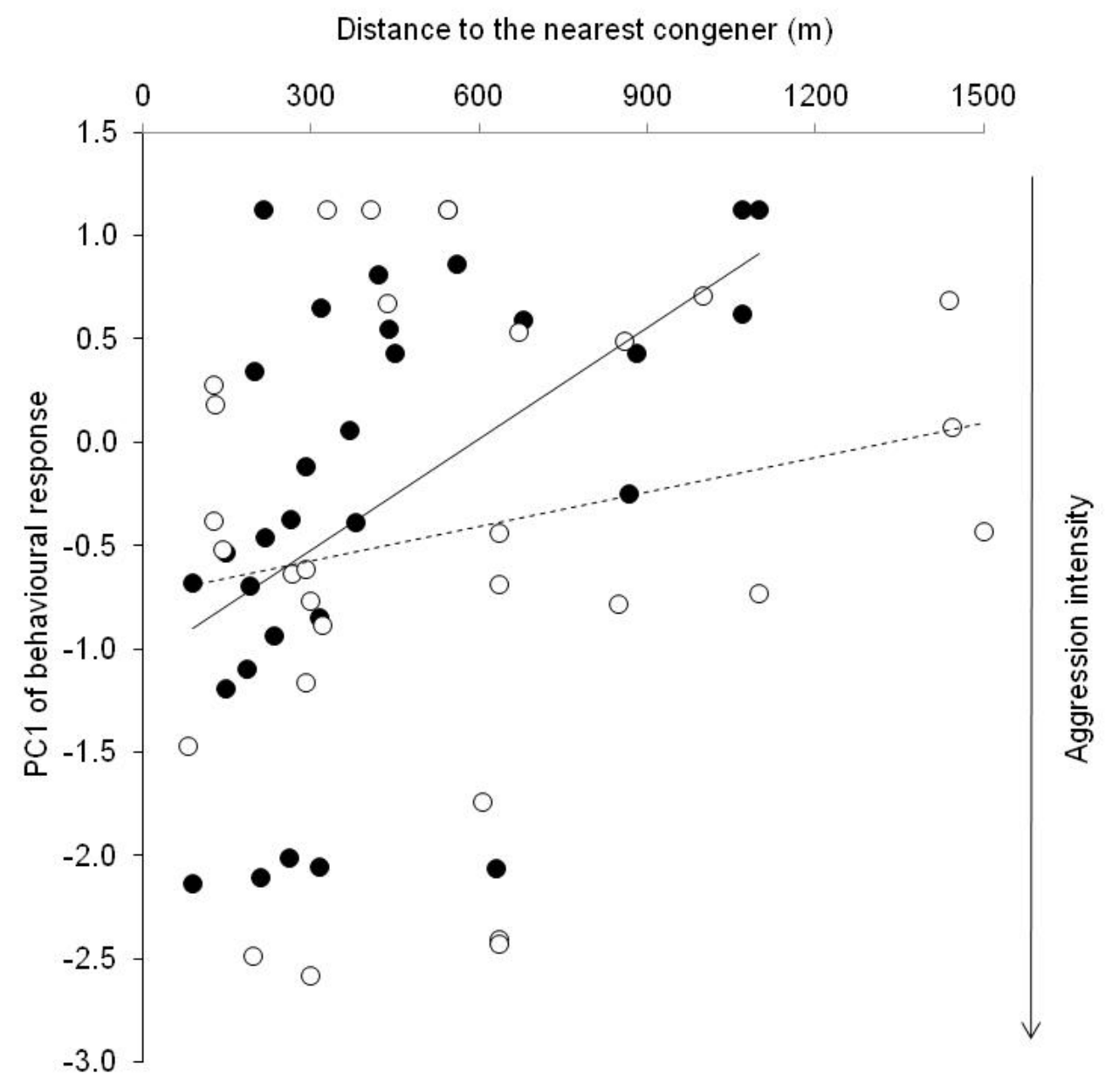

- Galerida theklae - Galerida cristata 